\title{
DUARTE PACHECO PEREIRA UM CARTOGRA- FO? O "ESMERALDO DE SITU ORBIS" UM ATLAS?
}

\author{
JUAQUIM BARRADAS DE CARVALHU \\ Professor de Históría da Clvilização Ibérica da Faculdade \\ de Filosofia, Ciênclas e Letras da Universidade de Såo \\ Paulo.
}

\section{2}

O Esmeraldo de situ orbis (1505-1508) (1) de Duarte Pacheco Pereira (c. 1460-1533) (2), obra complexa, obra-síntese, à imagem do seu autor, personagem complexa, personagem-síntese, revela-se-nos como um livro de história, com traços bem nítidos de crônica medieval, um livro de cosmografia e um regimento de navegação, um livro de geografia, sendo finalmente, e fundamentalmente, um roteiro. Duarte Pacheco Pereira classifica-a, êle próprio, como um livro de cosmografia e marinharia (3). Mas para além desta pluralidade de facetas, ainda alguns historiadores afirmaram ter ela sido um atlas. Podemos mesmo dizer que todos os autores que encararam a obra de Duarte Pacheco sob êste aspecto, a tomaram como tendo sido, no manuscrito original, um atlas. Assim, Diogo Barbosa Machado, em 1741, na sua Biblioteca Lusitana (4), afirma que o manuscrito original do Esmeraldo, que pertencia então à biblioteca do Marquês de Abrantes, continha 16 cartas e alguns desenhos. Na verdade, nos dois manuscritos-cópias que nos restam, o de Evora

(1). - Ver os nossos artigos,Esmeraldo de situ orbis e Duarte Pacheco Pereira no Dicionarto de Historia de Portugal dirigido por Joel Serräo, Iniciativas Editoriais, Lisboa, 1967. Ver ainda os nossos estudos: "Esmeraldo ae situ orbis" de Duarte Pacheco Pereira (Edition critique et commentée), no prelo; e principalmente: $L$ "Esmeraldo de situ orbis" de Duarte Pacheco Pereira et la littérature portugaise de voyages à l'époque des grandes découvertes, em preparação.

(2). - Ibiaem.

(3). - Ver o Prólogo do Livro I do Esmeraldo. Ver ainda o nosso estudo: As fontes de Duarte Pacheco Pereira no "Esmeraldo de situ orbis", Coleccko da "Revista de História", Sáo Paulo, 1967.

(4). - Utilizámos a 27 ediçáo, Lisboa, 1930, Tomo I, p. 722 . 
(5) e o de Lisboa (6), podemos verificar que os lugares ocupados pelas pretensas cartas são assinalados com as palavras: aqui mapa (7). Luciano Pereira da Silva, no seu estudo sôbre Duarte Pacheco Pereira - precursor de Cabral - (8), diz ter sido o autor do Esmeraldo um cartógrafo, além de navegador, soldado e roteirista. Armando Cortesão, na sua Cartografia e cartógrafos portuguêses dos séculos XV e XVI (Contribuição para um estudo completo) (9), pergunta-se se podemos considerar Duarte Pacheco Pereira como um cartógrafo. A dúvida parece dominar as palavras de Armando Cortesão, mas de maneira talvez contraditória, acaba por admitir o Duarte Pacheco Pereira cartógrafo, citando mesmo a opinião de Luciano Pereira da Silva. Ainda Armando Cortesão, em colaboração com Avelino Teixeira da Mota, na Portugaliae Monumenta Cartographica (10), volta a afirmar que o Esmeraldo de situ orbis no manuscrito original

\section{"continha 16 cartas e várias plantas relativas à África".}

Finalmente, Avelino Teixeira da Mota, no seu estudo sôbre $A$ evolução da ciência náutica durante os séculos XV-XVI na cartografia portuguêsa da época (11), afirma que

"o Esmeraldo, embora sendo fundamentalmente um roteiro, continha também cartografia, hoje infelizmente perdida...".

Se a dúvida pode ter existido no que diz respeito ao Duarte Pacheco Pereira cartógrafo, em contrapartida ela nunca existiu no que diz respeito ao atlas que teria também sido o Esmeraldo de situ orbis no seu manuscrito original.

Ora parece-nos que as cartas, com duas exceções apenas, não passavam de desenhos, de vistas de costa. O Esmeraldo de situ orbis nunca foi um atlas, e a fonte desta errônea opinião, geralmente ad-

(5) - Biblioteca Pública e Arquivo Distrital de fvora, Manuscrito CXV, 1-3.

(6) - Biblioteca Nacional (Lisboa), Seç̧áo de Reservados, Fundo Geral 888; cota antiga: Manuscrito B-17, 7. - O manuscrito de Lisboa é uma cópia do de Evora. O de Evora é da primeira metade do século XVIII. O de Lisboa é da segunda metade dêsse mesmo século. Ver o nosso estudo: "Esmeraldo de situ orbis" de Duarte Pacheco Pereira (Edition critique et commenté), no prelo.

(7) . - Livro I, Capitulo 13; L. I, Cap. 13; L. I, Cap. 14; L. I, Cap. 14; L. I. Cap. 15; L. I, Cap. 16; L. I, Cap. 17; L. I, Cap. 18; L. I. Cap. 18; L. I, Cap. 18; L. I, Cap. 22; I. I, Cap. 28; L. I, Cap. 33; L. II, Cap. 1; L. II, Cap. 10; L. III,Cap. 7.

(8) . - In História áa Colonizaçāo Portuguêsa do Brasil, volume I, Pôrto, 1921, ps. 231, 252, ou este mesmo estudo nas Obras Completas de Luciano Pereira da Silva, Volume II, Lisboa; 1945.

(9). - Lisboa, 1935, Volume I, ps. 105-106.

(10). - Lisboa, 1960, volume I, p. 179.

(11). - Ediçāo da Junta de Investigaçóes do Ultramar, Lisboa, 1961, p. 12. 
mitida, foi certamente a expressão aqui mapa, dezesseis vêzes empregada através do texto, mas cuja responsabilidade não pertence a Duarte Pacheco Pereira, mas sim aos copistas do século XVIII a quem devemos os manuscritos conhecidos.

Não existiram mais do que duas cartas através do texto do Esmeraldo: um mapa-múndi, cujo lugar é por duas vêzes indicado. representando a Europa, a Ásia, a África e a América (12), e uma carta das ilhas de Cabo Verde (13), onde se podiam ver traçadas as rotas marítimas e as direções dos ventos. Para além destas duas verdadeiras cartas, as restantes não eram mais do que desenhos, vistas de costa, tal como se podem ver em roteiros do século XVI, nomeadamente no Roteiro de Lisboa a Goa de D. João de Castro (14).

A leitura atenta da obra de Duarte Pacheco Pereira permitenos saber o que representavam os desenhos e vistas de costa. Assim, no manuscrito original, desaparecido, os desenhos representavam cidades, como Ceuta (15), Alcácer-Ceguer (16), Tânger (17),

(12). - "... e porque melhor se possa entender esta nossa obra, pusémos aquí pintado um mapa mundi da felção e descrição destas terras, no qual entrará a Europa, posto que dela não escrevamos, por ser uma das quatro partes do orbe, ainda que os antigos escritores aflrmaram serem três sómente, s. Europa, Ásła, e Africa, de que já atrás falámos,...". (Livro I, Capítulo 5). Tôdas as transcriçōes de passos do Esmeraldo são feltas segundo o texto crítico da nossa ediç̧o: "Esmeraldo de situ orbis" de Duarte Pacheco Pereira (Edition critique et commentée), no prelo.

- "... esta é a circunferência de tôda Áfl'tca, segundo se poderá ver na pintura do mapa mundi e tábua geral que adiante do dito quinto capitulo está;...". (L. III, Cap. 7).

(13) . - "Pols já temos escrito do cabo Verde, e como se antigamente chamou Aspérido promotório, assi devemos escrever das llhas que cem léguas em mar dêle estão, as quais também naquela Antigüidade foram chamadas Aspéridas, segundo diz Plínio na Natural História no seu sexto livro, capitulo trinta e um, e agora a principal delas chamamos ilha de São Tiago; as quais llhas sâo dez e mais dous grandes ilhéos; e por se isto melhor entender, pusémos aqui sua pintura e felçáo e como se correm com o dito cabo Verde e assi umas com as outras, e as rotas que cada uma tem". (L. I, Cap. 28) .

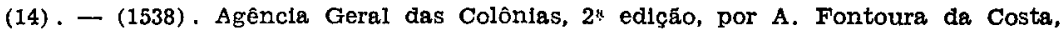
Lisbon, 1939, ps. 117, 120, 134, 144, 148, 149, 156, 173, 194.

(15). - "A ponta d'Almina é a própria parte do promontório da Ximeira que dos antigos escritores Ábila fol chamada, onde é situada a grande e excelente cldade de Cepta, da qual aqui pusémos sua figura, e assim do monte de Gibaltar pintada pelo natural, por este ser o princípio do nosso estreito oucidenta1;...". (L. I, Cap. 13).

(16) . - "... e porque isto se melhor entencia, pusémos aqui Alcáçre com alguma parte de sua terra pintado pelo natural;...". (L. I, Cap. 13).

(17) . - "... cldade de Tânger, a qual está cinco léguas além d'Alcáçre para róra do estreito, e no seu antigo princfplo Tingi houve nome, segundo diz Plínlo no seu quinto livro da Natural História, capitulo primeiro; o qual nome por muitos anos despois em Tanger lhe fol tornado; cuja pintura pelo natural e também do cabo d'Espartel aqui pusémos;...". (L. I, Oap. 14). 
Anifé (18), Safim (19); vilas, como Arzila (20), Larache (21), Salé (22), Almancora (23); aldeias, como Salé (24), Casa do Cavaleiro (25); cabos, como o cabo Espartel (26), o cabo de Sant'Ana (27), o cabo da Boa Esperança (28); baías, como a de Ma-

(18). - “... e a conhecença desta cidade d'Anife, a qual aqui pusémos pintada do natural,...". (L. I, Cap. 16) .

(19). - "... e adiante desta ponta do Canaveal pouco mals de mela légua está a cidade de Safi, trabutaria a Vossa Alteza, da qual aqui pusémos sua pintura natural;...". (L. I, Cap. 18).

(20) . - “... e por se isto melhor entender, pusémos aqui pintada pelo natural a vila d'Arzila com seu arrecife, na qual pintura vai uma caravela à vela dentro por onde deve ir:...". (L. I, Cap. 14).

(21). - “... e delas à boca do ro de Larache são duas léguas; e a entrada deste rio em nosso tempo é da banda do sudoeste, muito perto da pedra onde está um baluarte que tem dous cubelos, abalxo da vila de Larache junto com o rio, segundo se verá nesta pintura felta pelo natural que aqui pusémos;...". (L. I, Cap. 15).

(22) . - "O río da Mamora com o rlo e vila de Salé, a qual aquí pusémos pintada pelo natural, jazem nordeste e sudoeste e tem na rota sete léguas;...". (L. I, Cap. 15).

(23) . - "... e porque melhor isto se possa entender, pusémos aquí pintada pelo ntural a vila d'Almancora com uma arvore que tem por conhecença,...". (L. I, Cap. 16).

(24). - "...e em Salé são três lugares, dos quais os dous sòmente aqui pintamos,...". (L. I, Cap. 15).

(25) . - "Esta é a Casa do Cavaleiro, a qual os mouros em sua língua chamam Uguer, e por se melhor conhecer, a pusémos aqui pintada do natural,...". (L. I, Cap. 18) .

- "...e quem nesta Casa do Cavaletro houver de entrar e nela quiser surgir, veja esta pintura...". (L. I, Cap. 18) .

(26). - "...cidade de Tânger, a qual está cinco léguas além d'Alcaçre para fóra do estreito, e no seu antigo princíplo Tingl houve nome, segundo diz Plínio no seu quinto ltvro da Natural História, capítulo primeiro; o qual nome por muitos anos despois em Tânger lhe foi tornado; cuja pintura pelo natural e tambem do cabo d'Espartel aqui pusémos;...". (L. I, Cap. 14) .

(27) . - "...este cabo de Santa Ana sāo dezasseis léguas, e este se aparta em ladeza do círculo equinocial contra o polo ártico sete graos, e na demostração e pintura aquí posta se verá a felçáo desta terra". (L. II, Cap. 1).

(28). - "E adiante olto léguas da ponta da. Praia é achado um fermoso promontório a que nós chamamos o cabo de Boa Esperança, o qual Jaz com a ponta da Prala, nor-noroeste e su-sueste, e tem as ditas ofto léguas na rota como dito é; e este cabo se aparta em ladeza, do círculo da equinocial contra o polo antártico, trinta e quatro graos e trinta minutos; e adiante nesta outra folha se achará sua feiçăo pintada do natural,...". (L. III, Cap. 6) .

- “...por esta causa the pôs nome cabo de Boa Esperança, o qual se aparta em ladeza, do círculo da equinocial contra o polo antártico, trinta e quatro graos e trinta minutos, que fazem um melo grao, segundo é já dito no item que acima fica; $\epsilon$ esta terra é muito alta e da felgro que parece nesta pintura,...". (L. III, Cap. 7).

- "Já na demostração e pintura do cabo de Boa Esperança, que aqui é posta,...". (L. III, Cap. 8) . 
zagão (29) e a de Bezeguiche (30); montes e montanhas, como o monte de Gibraltar (31), e as montanhas da serra Lioa (32); rios, como o rio de Salé (33) e o rio das Palmas (34); fortalezas e castelos, tais como a fortaleza de Santa Cruz (35), e o castelo de São Jorge da Mina (36); caravelas (37), árvores (38), tôrres (39), divisas, como a do Infante D. Henrique (40), o pelicano de D.

(29). - “...e aqui fol antlgamente a cidade de Mazagáo, que agora é de todo destruida; e esta angra é bom porto pera naos grandes, a qual aqui pusémos pintada pelo natural;...". (L, I, Cap. 17).

(30). - "...angra de Bezeguiche, segundo parece nesta figura que aqui pelo natural pusémos pintada;...". (L. I, Cap. 28).

(31). - “A ponta d’Almina é a própria parte do promontórlo da Ximeira que dos antigos escritores Abila fol chamada, onde é situada a grande e excelente cidade de Cepta, da qual aqui pusémos sua figura, e assim do monte de Gibaltar pintada pelo netural, por este ser o príncípio do nosso estreito oucidental;...". (L. I, Cap. 13).

(32). - ". .a serra Lioa, da qual serra pusémos aqui a pintura pelo natural por se melhor entender;...". (L. I, Cap. 33).

(33). - "..este rio de Salé tem ua entrada da banda de les-sueste ao longo de um cubelo, e esta tem no canal duas braças e mela largas de prelamar d'água viva e a maré de nordeste e sudoeste; e da banda do sul tem outro canal, e antre estes dous canais tem ua restinga de pedra muito grande e, a lugares, d'areia, na qual rompe muito o mar; e a conhecença deste río é a torre de Salé, muito grande e alta e da felçáo que aqui está pintada,...". (L. I, Cap. 15).

(34). - "...e 1rá dentro no dito rio das Palmas, segundo se pode ver nesta pintura e demostraçáo;...". (L. II, Cap. 1).

(35) . - "...a qual fortaleza de Santa Cruz pusémos aqui pintada pelo natural, por se melhor entender". (L. I, Cap. 20).

(36). - "...agora convém que digamos como o serenissimo Principe, Rel Dom Joăo de Portugal, seu filho, despois da morte de seu padre, mandou fazer do primeiro fundamento o castelc. de Sấo. Jorge da Mina;.......... e porque se melhor possa entender, o pusémos aqui pintado pelo natural segundo agora em nossos dias é felto". (L. Ir, Cap. 5).

- "...portanto seguiremos nosso caminho, notando qualquer ledor como do castelo de São Jorze três léguas adiante, no fim đa enseada que se ali faz, parece um promontório, a que nós chamamos o cabo do Corço, o qual faz de si um rostro redondo, que tem ua árvore sobre si, e esta se não vê senão estando perto de terra, a qual demostraçăo parece na pintura do dito castelo, que atrás fica". (L. II, Cap. 6).

(37). - "...todo o navio que houver de pousar em Alcáçre, veja na bala aonde está ua caravela pintada, e se for navio pequeno, poderá all pousar, e se for grande, algum tanto mais ao mar". (L. I, Cap. 13) .

- “...e por se isto melhor entender, pusémos aqui pintada pelo natural a vila d'Arzlla com seu arrecife, na qual pintura val ua caravela a vela pera dentro por onde deve $\operatorname{tr} ; . . . "$. (L. I, Cap. 14) .

(38) . - "...e porque isto melhor se possa entender, pusémos aqui pintada pelo natural a vila d'Almancora com ia árvore que tem por conhecença,...". (L. I, Cap. 16).

(39) . - “... e a conhecença dêste rio é a torre de Salé, muito grande e alta e da felção que aquí está plntada, que náo há outra tal em tôda esta costa;...". (L. I, Cap. 15).

(40). - “..e porque dos tais prínctpes é razío que flquem em memórla suas cousas, portanto pusémos aqui pintada sua divisa e o seu moto, assi como o êle trazia escrito em língua francesa". (L. I, Cap. 22). 
João II (41), e o globo de D. Manuel I (42). E tudo, segundo as próprias palavras de Duarte Pacheco Pereira, pintado do natural.

$\mathrm{O}$ problema que nos resta resolver é o de saber se Duarte $\mathrm{Pa}-$ checo Pereira foi o autor das duas únicas cartas e dos desenhos e vistas de costa que se distribuem ao longo do texto da sua obra. Seríamos levados a pronunciarmo-nos afirmativamente, tendo em conta as frases que com o assunto se relacionam e que podemos ver em 33 passos do texto da obra de Duarte Pacheco Pereira, não incluindo as 16 indicações onde se lê aqui mapa. Em 22 dêstes 33 passos, Duarte Pacheco escreve explìcitamente: ...pusémos aqui pintado um mapa..., ou uma expressão eqüivalente (43). Existem

(41). - “..tomou por devisa um pelicano, que aqui pusémos pintado,...". (L. III, Prólogo) .

(42) . “...e bem se mostrou a esfera que tomou por divisa, que aqui pusémos, ser ua profecia do que vimos, por onde parece que Sua Alteza alcançou o fim desejado; a glória do qual Deos acrecente aqui a esfera"'. (Livro IV, Prólogo) .

(43) . - "..pusémos aqui plntado um mapa mundi...". (L, I, Cap. 5) .

- “...a grande e excelente cidade de Cepta, da qual aqui pusémos sua fisura, e assim do monte de Gibaltar pintada pelo natural,...". (L. I, Cap. 13) .

- "...pusémos aqui Alcáçre com algua parte de sua terra pintado pelo natural;...". (L. I, Cap. 13).

- "...cidade de Tânger... cuja pintura pelo natural e também do cabo d'Espartel aqui pusémos;...". (L. I, Cap. 14).

- “...pusémos aqui pintada pelo natural a vilä d'Arzila...". (I. I, Cap. 14).

- "...e a entrada deste rio (rio de Larache) em nosso tempo é da banda do sudoeste, muito perto da pedra onde está um baluarte que tem dous cubelos, abaixo da vila de Larache junto com o rio, segundo se verá nesta pintura feita pelo natural, que aquí pusémos;...". (L. I, Cap. 15).

- "O rio da Mamora com o rio e vila de Salé, a qual aqui pusémos pintada pelo natural,...". (L. I, Cap. 15).

- “...e em Salé sắo três lugares, dôs quais os dous sòmente aqui pintamos,...". (L. I, Cap. 15).

-....pusémos aqui pintada pelo natural a vlla d'Almancora...". (L. I, Cap. 16).

— "...cidade d'Anjfé, a qual aqui pusémos pintada do natural...". (L. I, Cap. 16).

- "..esta angra (de Mazagão)... a qual aqui pusémos pintada pelo natural;...". (L. I, Cap. 17) .

- "Esta é a Casa do Cavaleiro, a cual... a pusémos aqui pintada do natural,...". (L. I, Cap. 18).

- "...a cidade de Safi... da qual aqui pusémos sua pintura natural;...". (L. I, Cap. 18)

- "...a qual fortaleza de Santa Cruz pusémos aqui pintada pelo natural,...". (L. I, Cap. 20) .

- "...pusémos aqui pintada sua divisa e o seu moto (do Infante D. Henrique), assi como o ele trazia escrito em lingua francesa". (L. I, Cap. 22)

- "...angra de Bezeguiche, segundo parece nesta figura que aqui pelo natural pusémos pintada;...". (I, T, Cap. 28) .

- "Pols jé temos escrito do cabo Verde... assi devemos escrever das $11 \mathrm{has}$ cue cem léguas em mar dele estão... a principal delas chamamos tha de Săo Tiago; as quais llhas săo dez e mais dous grandes llhéos; e por se tsto melhor entender, pusémos aquí sua pintura e felção e como se correm com o dito cabo Verde e assi uas com as outras, e as rotas que cada 
ainda 6 outros passos em que o sentido é o mesmo, ainda que menos explícito. O primeiro faz alusão a Alcaçre (44) e liga-se a um passo anterior em que se lê: ...pusémos aqui Alcaçre... pintado pelo natural... (45); o segundo faz alusão à tôrre de Salé (46) e liga-se ao passo anterior: ...o rio e vila de Salé, a qual áqui pusémos pintada pelo natural... (47); o terceiro e o quarto fazem alusão à Casa do Cavaleiro (48) e ligam-se a um outro passo onde podemos ler: ...e por se melhor conhecer a pusémos aqui pintada do natural. . . (49); o quinto passo, fazendo alusão ao Cabo do Corço (50), liga-se a um passo anterior sôbre o Castelo de São Jorze da Mina, o qual ...pusémos aqui pintado pelo natural... (51); enfim, o sexto e último passo liga-se ao mapa-múndi (52) e ao seguinte passo: ...pusémós aqui pintado um mapa mundi... (53).

Podemos agora concluir que em 22 mais 6 , isto é, em 28 passos do Esmeraldo, Duarte Pacheco Pereira escreve de maneira a poder-nos fazer supor que foi êle próprio o autor das duas cartas, dos desenhos, e das vistas de costa. Entre os 33 passos, não há senão 5 cujo sentido é diferente, se bem que esta diferença não nos permita concluir que Duarte Pacheco Pereira não tenha sido o seu autor. Dêstes 5 passos, três dizem respeito ao Cabo da Boa Espe-

ua tem". (L. I, Cap. 28).

- "...a serra Lioa, da qual serra pusénıos aqui a pintura pelo natural...". (L. I, Cap. 33) .

- "...e porque se melhor possa entender, o pusémos (o Castelo de sfóo Jorge da Mina) aqui pintado pelo natural segundo agora em nossos dias é felto;...". (L. II, Cap. 5).

- "...porquanto esta serra e llha (Fernão do Pó) está adiante do derradelro rio, dos quatro de que atrás falámos, cinco léguas de caminho, e é tal que em toda a Guiné náo há i outra de tal feiçáo, por isso pusémos aqui sua pintura natural;...". (L. II, Cap. 10).

- "...tomou (Dom Joăo II) por devisa um pelicano, que aqul pusémos pintado,...". (L. III, Prólogo) .

- "...e bem se mostrou a esfera que tomou (D. Manuel) por divisa, que aquil pusémos...". (L. IV, Prólogo).

(44). - L. I, Cap. 13

(45). - L. I, Cap. 13.

(46). - L. I, Cap. 15.

(47). - L. I. Cap. 15.

(48). - L. I, Cap. 18; L. I, Cap. 18.

(49). - L. I, Cap. 18.

(50). - L. II, Cap. 6.

(51). - L. II, Cap. 5.

(52). - L. III, Cap. 7 .

(53) . - L. I, Cap. 5. 
rança (54), e os dois que restam, um ao Cabo de Sant'Ana (55) e o outro ao rio das Palmas (56).

Em consequiência .Duarte Pacheco Pereira cartógrafo? Ou autor de desenhos, e de vistas de costa?

Não podemos, parece-nos, considerá-lo como cartógrfo e partir das duas únicas cartas do texto, das quais uma é um mapa-múndi que êle, muito provàvelmente, tirou de outro lado. Diríamos, pois, que a conclusão com maiores probabilidades de ser verdadeira a retirar-se da análise dos textos seria a que lhe atribuiria a autoria dos desenhos e das vistas de costa.

Mas, assim mesmo, nada de menos seguro. Quando Duarte Pacheco Pereira escreve: . . pusémos aqui Alcaçre com algua parte de sua terra pintado pelo natural; ..., ou uma expressão eqüivalente, não podemos legitimamente daí deduzir que os desenhos, as vistas de costa, que êle aí colocou tenham sido da sua autoria. Podemos, quando muito, supô-lo, mas nunca afirmá-lo categòricamente.

Duas conclusões, entretanto, são legítimas: em primeiro lugar, Duarte Pacheco Pereira não foi cartógrafo, nem o Esmeraldo de situ orbis foi um altas; em segundo lugar, o Esmeraldo de situ orbis foi, no manuscrito original, um livro ilstrado com desenho e vistas de costa, quer tenha sido ou não dêles ou delas autor Duarte Pacheco Pereira. Livro ilustrado com desenhos e vistas de costa, para além do livro de história, com traços bem nítidos de crônica medieval, do livro de cosmografia e do regimento de navegação, do livro de geografia, e finalmente do roteiro que êle foi fundamentalmente.

\footnotetext{
(54) . - “...e adiante nesta outra folha se achará sua felç̣o (do Cabo da Boa Esperança) pintada do natural...". (L. III, Cap. 6).

- “...esta terra (Cabo da Boa Esperança) é muito alta e da felçáo que parece nesta pintura,...". (L. III, Csp. 7) .

- "Já na demostraçăo e pintura do cabo de Boa Esperança, que aquí é posta,...". (L. III, Cap. 8).

(55) - - "..e este (Cabo de Santa Ana) se aparta em ladeza do circulo equinocial contra o polo ártico sete graos, e na demostração e pintura aquł posta se verá a felção desta terra". (L. II, Cap. I).

(56). - "...e irá dentro no dito rio das Palmas, segundo se pode ver nesta pintura e demostração;...". (L. II, Cap. 1).
} 